\title{
Lodging Resistance of Aromatic CMS Line Zhongzhe $A$ and Its Derived Lines
}

\section{Peng Zhang, Kunjun Ouyang, Zhengzheng Zhong, Yu Gao, Zhihua Tong, Shuirong Sun, Hanhua Tong*}

China National Rice Research Institute, State Key Laboratory of Rice Biology, Hangzhou, China

Email: *htonghz@126.com

How to cite this paper: Zhang, P., Ouyang, K.J., Zhong, Z.Z., Gao, Y., Tong, Z.H., Sun, S.R. and Tong, H.H. (2019) Lodging Resistance of Aromatic CMS Line Zhongzhe A and Its Derived Lines. American Journal of Plant Sciences, 10, 351-368. https://doi.org/10.4236/ajps.2019.103026

Received: January 18, 2019

Accepted: February 26, 2019

Published: March 1, 2019

Copyright $\odot 2019$ by author(s) and Scientific Research Publishing Inc. This work is licensed under the Creative Commons Attribution International License (CC BY 4.0).

http://creativecommons.org/licenses/by/4.0/

\begin{abstract}
Nineteen rice combinations derived from Zhongzhe A and its derived lines, as well as Y Liangyou 1 as the control, were used to study lodging resistance by detecting plant height and some of the traits of culm and panicle that are related to lodging. The results indicated that the lodging resistance of 16 combinations was significantly stronger than that of $\mathrm{Y}$ Liangyou 1. Moreover, the lodging resistances of all combinations derived from Zhongzhe $2 \mathrm{~A}$, Zhongzhe 3A, Huazhe A and Zhong $1 \mathrm{~A}$ were significantly higher than that of $\mathrm{Y}$ Liangyou 1. Additionally, the traits related to lodging were not identical within different CMS rice lines, and the relationship between plant height and lodging resistance was only significantly $(P<0.01)$ detected in Zhongzhe 2A. Some traits of the second internode were closely related to lodging in all combinations, which can be used as an effective index in lodging resistance breeding in rice.
\end{abstract}

\section{Keywords}

Cytoplasmic Male Sterile Line, Derived Lines, Lodging Resistance, Rice

\section{Introduction}

Oryza sativa L. is one of the most important food crops in the world, and its yield is directly related to the food security of the country. In recent years, with the widespread application of super rice, cultivation and cultivation methods such as less tillage, no tillage, transplanting seedlings, and direct seeding; and the excessive application of fertilizer, the lodging phenomenon of rice is becoming increasingly widespread. Lodging has become a major obstacle to achieving a high yield of rice. The earlier the lodging is, the greater the impact on yield. The lodging of rice not only causes a decrease in production but also affects the qual- 
ity of rice, and it is time-consuming to harvest. After the lodging of rice during production, photosynthesis will generally decrease by approximately $60 \%-80 \%$, and if the lodging is increased by $2 \%$, the yield will be reduced by $1 \%$ [1] [2].

It is the precondition and the basis for the study of the lodging resistance of rice to establish an objective and scientific evaluation method to accurately identify the traits related to lodging in rice. Many studies have shown that the resistance of rice is closely related to the characteristics of plant height, stalk strength, spike type factor and so on. It is generally believed that the height of the plant is positively correlated with lodging, and reducing plant height is the most effective measure to reduce lodging [3] [4]. However, Zhang et al. [5] found that the height of the plant was not directly related to lodging resistance in a certain range. A study by Shen et al. [6] also found that the higher varieties are not necessarily prone to lodging, and the shorter varieties do not necessarily avoid lodging. Studies on the related characteristics of rice stalk show that the elongation length, the fullness (fresh weight), the stem roughness, the stem wall thickness, the biomass yield and other stem morphological characteristics are closely related to the lodging resistance of the crops [3] [7] [8] [9] [10] [11]. Some scholars have studied the relationship between spike type and lodging by measuring the center of gravity and the bending moment. It is considered that the spike type can affect lodging resistance by bending the force-bend distance and center of gravity, thus increasing the bending distance and the center of gravity, decreasing lodging resistance, and, conversely, increasing the lodging resistance [12] [13] [14] [15].

Because of the different research materials and methods, there is no consistent evaluation index and method in the study of rice lodging. Zhongzhe $\mathrm{A}$ is a high-quality CMS line selected from the Chinese Rice Research Institute [16]. It is equipped with Zhongzheyou 1 and Zhongzheyou 8, with a batch from the Zhongzheyou series; due to its characteristics of good plant type, excellent quality, and high yield, it has been widely used in production [17]. In this paper, the high-quality aromatic CMS line Zhongzhe A and its derivative materials were used as experimental materials; in order to improve the lodging resistance of the series of hybrid rice varieties, the hybrid rice variety Y Liangyou 1, with the largest area of production promotion in recent years, was used as a control to further the research on the lodging resistance of the combination of the Zhongzheyou series and provide references for the cultivation of lodging-resistant varieties.

\section{Materials and Methods}

\subsection{Materials}

The research material originates from the group of 6 CMS lines from Zhongzhe A and its derivative lines, which are composed of 19 parts, including Zhongzheyou 1, Zhongzheyou 8 and Zhongzheyou 10, which were hybridized from Zhongzhe A and registered by crop variety approval committee of many provinces in China. The hybrid rice variety Y Liangyou 1, with the largest area in the country in recent years, has been used as a control (Table 1). A total of 20 rice materials 
Table 1. Plant height and panicle characters of rice combinations in the study

\begin{tabular}{|c|c|c|c|c|c|}
\hline Combinations & Plant height $(\mathrm{cm})$ & Grain number per panicle & Panicle length $(\mathrm{cm})$ & Grain density & Fresh weight of panicle $(\mathrm{g})$ \\
\hline CK & $122.85 \pm 3.04$ & $252.30 \pm 42.76$ & $32.23 \pm 2.01$ & $7.80 \pm 0.98$ & $6.77 \pm 1.09$ \\
\hline 1 & $123.04 \pm 2.85$ & $309.60 \pm 28.07^{\mathrm{a}}$ & $28.90 \pm 0.80$ & $10.70 \pm 0.76$ & $7.63 \pm 0.72$ \\
\hline 2 & $119.16 \pm 2.70^{\mathrm{a}}$ & $264.90 \pm 35.52$ & $29.85 \pm 1.50$ & $8.80 \pm 0.87$ & $5.84 \pm 0.68$ \\
\hline 3 & $124.26 \pm 3.56$ & $298.50 \pm 61.44^{\mathrm{b}}$ & $29.64 \pm 1.88$ & $10.02 \pm 1.70$ & $6.67 \pm 1.41$ \\
\hline 4 & $116.44 \pm 6.85^{\mathrm{a}}$ & $239.90 \pm 31.47$ & $30.62 \pm 2.11^{\mathrm{b}}$ & $7.82 \pm 0.67$ & $6.06 \pm 0.86$ \\
\hline 5 & $127.10 \pm 4.99^{\mathrm{a}}$ & $223.40 \pm 33.28$ & $28.11 \pm 1.06^{\mathrm{a}}$ & $7.92 \pm 0.92$ & $5.79 \pm 0.87$ \\
\hline 6 & $128.84 \pm 5.84^{\mathrm{a}}$ & $253.10 \pm 29.75$ & $29.72 \pm 1.23$ & $8.51 \pm 0.89$ & $6.18 \pm 1.22$ \\
\hline 7 & $110.11 \pm 5.61^{\mathrm{a}}$ & $346.50 \pm 72.66^{\mathrm{b}}$ & $29.10 \pm 1.90^{\mathrm{b}}$ & $11.88 \pm 2.24^{\mathrm{a}}$ & $5.36 \pm 1.10^{\mathrm{a}}$ \\
\hline 8 & $118.59 \pm 3.39^{\mathrm{a}}$ & $345.00 \pm 37.60^{\mathrm{b}}$ & $30.61 \pm 1.19$ & $11.26 \pm 0.98^{\mathrm{a}}$ & $7.38 \pm 0.89$ \\
\hline 9 & $111.93 \pm 2.61^{\mathrm{a}}$ & $285.70 \pm 40.58$ & $25.40 \pm 1.10^{\mathrm{a}}$ & $11.22 \pm 1.33^{\mathrm{a}}$ & $5.16 \pm 0.73^{\mathrm{a}}$ \\
\hline 10 & $107.60 \pm 2.70^{\mathrm{a}}$ & $289.50 \pm 43.27$ & $28.27 \pm 1.18^{\mathrm{a}}$ & $10.23 \pm 1.36$ & $5.72 \pm 0.92^{\mathrm{b}}$ \\
\hline 11 & $119.39 \pm 3.72^{\mathrm{a}}$ & $290.70 \pm 39.31$ & $27.42 \pm 1.06^{\mathrm{a}}$ & $10.59 \pm 1.33$ & $6.86 \pm 0.62$ \\
\hline 12 & $110.82 \pm 2.45^{\mathrm{a}}$ & $310.30 \pm 40.35^{\mathrm{b}}$ & $28.42 \pm 1.10^{\mathrm{b}}$ & $10.91 \pm 1.35^{\mathrm{b}}$ & $6.75 \pm 1.22$ \\
\hline 13 & $114.41 \pm 2.60^{\mathrm{a}}$ & $338.60 \pm 25.97^{\mathrm{a}}$ & $26.99 \pm 1.16^{\mathrm{a}}$ & $12.55 \pm 0.92^{\mathrm{a}}$ & $7.86 \pm 0.90^{\mathrm{b}}$ \\
\hline 14 & $120.35 \pm 3.59^{b}$ & $263.00 \pm 43.94$ & $27.97 \pm 1.33^{\mathrm{a}}$ & $9.40 \pm 1.48$ & $6.25 \pm 1.22$ \\
\hline 15 & $126.39 \pm 2.55^{\mathrm{a}}$ & $293.90 \pm 34.89^{\mathrm{b}}$ & $26.66 \pm 1.20^{\mathrm{a}}$ & $11.02 \pm 1.17^{\mathrm{a}}$ & $6.72 \pm 0.65$ \\
\hline 16 & $123.45 \pm 3.65$ & $288.10 \pm 39.32$ & $28.60 \pm 1.61^{\mathrm{a}}$ & $10.07 \pm 1.21$ & $6.21 \pm 0.62$ \\
\hline 17 & $120.62 \pm 2.76^{\mathrm{b}}$ & $262.30 \pm 33.18$ & $28.28 \pm 3.25^{\mathrm{a}}$ & $9.39 \pm 1.59$ & $5.87 \pm 0.69$ \\
\hline 18 & $116.75 \pm 3.04^{\mathrm{a}}$ & $279.50 \pm 42.15$ & $29.84 \pm 1.98$ & $9.33 \pm 0.93$ & $6.34 \pm 0.98$ \\
\hline 19 & $116.11 \pm 3.96^{\mathrm{a}}$ & $251.10 \pm 52.39$ & $30.29 \pm 2.03$ & $8.23 \pm 1.31$ & $5.79 \pm 1.15^{\mathrm{b}}$ \\
\hline
\end{tabular}

Note: CK, Y liangyou 1; 1, Zhongzhe A/TP15; 2, Zhongzhe A/TP37; 3, Zhongzhe A/TP49; 4, Zhongzheyou 1; 5, Zhongzheyou 8; 6, Zhongzheyou 10; 7, Zhongzhe 2A/TP7; 8, Zhongzhe 2A/TP36; 9, Zhongzhe 2A/TP37; 10, Zhongzhe 2A/TP66; 11, Zhongzhe 3A/TP49; 12, Zhongzhe 8A/TP18; 13, Zhongzhe 8A/TP37; 14, Zhongzhe 8A/TP40; 15, Zhongzhe 16A/TP15; 16, Zhongzhe 16A/TP37; 17, Zhong 1A/TP15; 18, Zhong 1A/TP18; 19, Zhong 1A/TP37. a, b indicates 0.01 and 0.05 significant, respectively. The same as the following.

were planted in the summer of 2016 in farm of China Rice Research Institute, Fuyang, Zhejiang Province, $\left(30.07^{\circ} \mathrm{N} ; 119.95^{\circ} \mathrm{E}\right)$. The farm is located where the area is characterized by a subtropical monsoon climate with mean temperatures of $24.3^{\circ} \mathrm{C}$, ranging from $16^{\circ} \mathrm{C}$ in May to $38^{\circ} \mathrm{C}$ in August, with approximately $80 \%$ falling between May and September. The soil in this farm is a ferric-accumulic, stagnic anthrosol. Plants were sown on May 25 and transplanted once on June 20 , and seedlings were collected at $25 \mathrm{~d}$. The planting area of each material was $33.4 \mathrm{M}^{2}$, and the planting density was $23.1 \mathrm{~cm} * 26.4 \mathrm{~cm}$; planting was repeated twice. Due to the differences in the growth periods of different materials, the sampling time in the field was 21 to 28 days after panicle.

\subsection{Experimental Methods}

The characters of 20 test materials, including plant height, stem correlative characters and spike type factor, were investigated. Each material randomly included 10 strains. As the difference between two replications was not significant, 
the average value of 20 measurements of each trait was taken for statistical analysis. The specific measurement method is as follows:

1) Height $(\mathrm{cm})$ : the distance from the ground to the highest point of the plant (excluding awn);

2) of each segment $(\mathrm{cm})$ : from the first section of the plant above ground, the length of 4 internodes of the stem at the rice plant above ground;

3) Fresh quality from the base to top of each internode (g): weight of the fresh mass from the base of each section to the top of the ear;

4) Dry quality of each section $(\mathrm{g})$ : the dry weight from 4 sections to be included in the oven, after filming at $105^{\circ} \mathrm{C}$ for 30 min, baking at $80^{\circ} \mathrm{C}$ for $12 \mathrm{~h}$;

5) Flexural strength of each section $(\mathrm{N})$ : fixed ends of each section hook at the middle of the stem with a weight weighed just after the stem breaks and multiplied by $9.8 \mathrm{~N} / \mathrm{kg}$;

6) Outside diameter of each section $(\mathrm{cm})$ : the external diameter of each section measured with a digital display Vernier caliper, and the standard unified to measure the external diameter at $2 \mathrm{~cm}$ from the base of the distance section. The calculation formula was (the outer diameter at the roughest part + the outer diameter at the smallest part)/2.

7) Spike length $(\mathrm{cm})$ : the length of the spike stem node to the top of the spike (not including the awn) measured with a ruler;

8) Fresh ear weight (g): weight of the fresh weight of each ear;

9) Number of grains per panicle: the number of grains per panicle;

10) Grain density: ratio of the number of grains per panicle to the length of panicle;

11) The bending moment: the length from the base of the node to the top of the ear $\times$ the fresh mass from the base of the joint to the top of the spike $\times 9.8$.

\subsection{Calculation and Evaluation of Lodging Index}

Lodging index $=$ bending moment/resistance $\times 100 \%$. The greater the lodging index is, the easier the stalks fall down, and lodging index 200 is the critical value for lodging resistance [3] [18].

\subsection{Analytical Statistical Methods}

The correlation analysis and single factor variance analysis (Duncan multiple comparison) of rice lodging-related traits were performed by SPSS 18.0 statistical analysis software. Origin 7.5 analysis software was used.

\section{Results}

\subsection{Plant Height and Spike Character of the Test Materials}

The height of the 19 test materials ranged from $110-130 \mathrm{~cm}$, and that of the control Y Liangyou 1 was $122.8 \mathrm{~cm}$. Among them, the combinations of Zhongzhe A and Huazhe A were relatively high (above $120 \mathrm{~cm}$ ), and the plant heights of combinations of Zhongzhe $2 \mathrm{~A}$ and Zhongzhe $8 \mathrm{~A}$ were relatively short (below 
$120 \mathrm{~cm})($ Table 1$)$.

The number of grains per panicle for the 19 test materials was between 223.40 - 346.50. Among them, the combinations of Zhongzhe 2A and Huazhe A were more than 280, which was higher than the control Y Liangyou 1 (252.30), and the grain density ranged from 10.23 to 12.55 , which was higher than that of the control Y Liangyou 1 (Table 1).

The fresh panicle weight of the control Y Liangyou 1 was $6.77 \mathrm{~g}$, while in 19 test materials, the fresh weight per panicle $(7.86 \mathrm{~g})$ of Zhongzhe 8A/TP37 was significantly higher $(P<0.05)$ than that of the control Y Liangyou 1. The fresh panicle weights of Zhongzhe 2A/TP7, Zhongzhe 2A/TP37, Zhongzhe 2A/TP66 and Zhong 1A/TP37 were significantly lower than that of the control Y Liangyou 1, while the remaining 14 were not significantly different between the fresh panicle weight and the control Y Liangyou 1 (Table 1).

\subsection{Characteristics of the Main Stems of the Test Material}

Among the 19 test materials, the lengths of the $1^{\text {st }}$ and $2^{\text {nd }}$ sections were shorter than in the comparison of Y Liangyou $1(11.01 \mathrm{~cm}$ and $19.16 \mathrm{~cm})$, of which the longest among the $1^{\text {st }}$ section was Zhong $1 \mathrm{~A} / \mathrm{TP} 15(10.75 \mathrm{~cm})$, the shortest was Zhongzhe 2A/TP66 $(7.37 \mathrm{~cm})$, and the longest was between the $2^{\text {nd }}$ section of Zhongzhe A/TP37 $(15.44 \mathrm{~cm})$ and the shortest for Zhongzhe 2A/TP37 $(9.08 \mathrm{~cm})$. The longest lengths between the $3^{\text {rd }}$ and $4^{\text {th }}$ sections were Huazhe A/TP37 and Zhongzheyou 8, respectively, and the shortest were Zhongzhe 2A/TP37 and Zhongzhe 8A/TP18 (Table 2).

The outer diameter of the first section of Zhongzhe 2A/TP66 was the same as that of the control Y Liangyou 1, both of which were $0.74 \mathrm{~cm}$. The outer diameter of the first section of the other 18 materials was thicker than the control, and the thickest one was Zhongzhe 3A/TP49., which reached $1.02 \mathrm{~cm}$, very significantly different from the control $(P<0.01)$. In addition to the $2^{\text {nd }}$ section of Zhongzheyou 1, the outside diameter is finer than the control, as well as the $2^{\text {nd }}$-section OD and control of Zhongzhe A/TP37 and Zhongzhe 2A/TP7. The other materials were thicker than those in the $2^{\text {nd }}$ section, of which the thickest was Zhongzhe 3A/TP49, which reached $0.85 \mathrm{~cm}$, and the control Y Liangyou 1 was only $0.66 \mathrm{~cm}$, with a significant difference compared to the control $(P<$ 0.01). The coarsest outer diameters of sections 3 and 4 were Zhongzhe 3A/TP49, and the shortest was Zhongzheyou 1 (Table 2).

Among the 19 tested materials, except for the dry weight of the first section, Zhongzheyou 8 was lower than that of the control Y Liangyou 1, and the dry weight of the first section of the other 18 materials was higher than that of the control, among which Zhongzhe 8A/TP37 was the highest, reaching $0.58 \mathrm{~g}$, which was extremely significant compared with the control $(P<0.01)$. The highest dry matter weight in sections 2 and 3 was Zhongzhe 2A/TP37, which was significantly higher than that of the control $(P<0.01)$. The highest dry matter weight in section 4 was Zhongzhe 8A/TP37, which was significantly higher than 


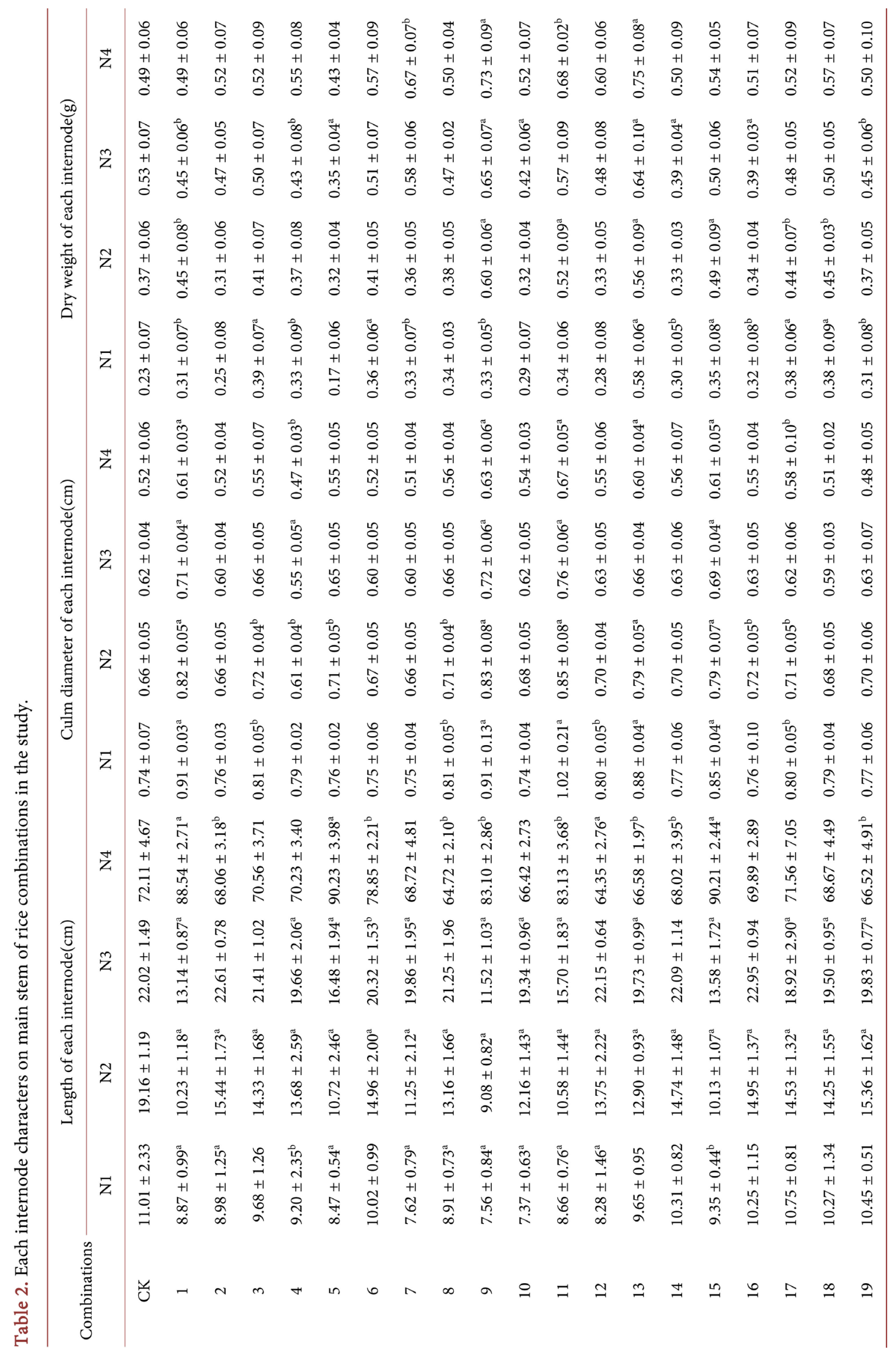


that of the control. The highest dry matter weight in section 4 was Zhongzhe 8A/TP37, which was significantly higher than the control. There was no significant difference in dry weight between the three sections of Zhongzhe 2A/TP37 and Zhongzhe 8A/TP37 (Table 2).

\subsection{The Bending Force between the Main Stems of the Test Material at Each Node}

Among the 19 tested materials, the bending moments, the internodes to the tip weight and the flexural strength of the joints of Zhongzhe A/TP15, Zhongzhe $3 \mathrm{~A} / \mathrm{TP} 49$ and Huazhe A/TP15 were significantly higher $(P<0.01$ or $P<0.05$, respectively) than the control $\mathrm{Y}$ Liangyou 1 , and the flexural strength of each section of Zhongzhe 2A/TP37 was significantly higher than that of the control ( $P$ $<0.01)$. The bending moments, the weight from the base of the internode to the top of the ear and the bending resistance of the joints of Zhongzhe A/TP37, Zhongzhe A/TP49, Zhongzheyou 10, Zhongzhe 8A/TP40 and Zhong 1A/TP15 showed no significant difference from the control (Table 3 ).

\subsection{The Lodging Resistance of the Tested Materials}

Among the 19 tested materials, the lodging index of 13 materials such as Zhongzhe A/TP15, Zhongzhe A/TP37, Zhongzhe 2A/TP36, Zhongzhe 2A/TP7, Zhongzhe 2A/TP66, Zhongzhe 2A/TP37, Zhongzhe 3A/TP49, Huazhe A/TP37, Huazhe A/TP15, Zhongzhe 8A/TP18, Zhong 1A/TP15, Zhong 1A/TP18 and Zhong 1A/TP37 was compared with that of the control $Y$ Liangyou 1 and found to have a significant difference $(P<0.01)$, while the lodging index of 3 materials, including Zhongzhe A/TP49, Zhongzhe 8A/TP37 and Zhongzheyou 8, was significantly different from that of $\mathrm{Y}$ Liangyou $1(P<0.05)$. The lodging index of three materials, including Zhongzheyou 1, Zhongzheyou 10 and Zhongzhe 8A/TP40, was not significantly different from that of Y Liangyou 1. Except for the middle $1 \mathrm{~A} / \mathrm{TP} 40$, the lodging index of the other 18 test materials was smaller than that of the control Y Liangyou 1, among which the lodging index of all combination materials was finely represented by Zhongzhe 2A, Zhongzhe 3A, Huazhe A and Zhong 1A but was less than Y Liangyou 1, among which Zhongzhe 2A/TP66 and Zhongzhe 3A/TP49 showed strong lodging resistance, and the lodging index was less than 200 (Figure 1).

\subsection{Analysis of the Lodging Correlation between Different CMS Lines}

There were significant correlations between the 13 characters and lodging indices in 6 Zhongzhe A-group materials. The $1^{\text {st }}$ section length was significantly positively correlated with lodging index $(P<0.01)$, the $2^{\text {nd }}$ and $3^{\text {rd }}$ internodes were significantly positively correlated with the lodging index $(P<0.05)$, and the $1^{\text {st }}$ section diameter, number of grains per spike and grain density were significantly negatively correlated with the lodging index $(P<0.01)$. There was a 


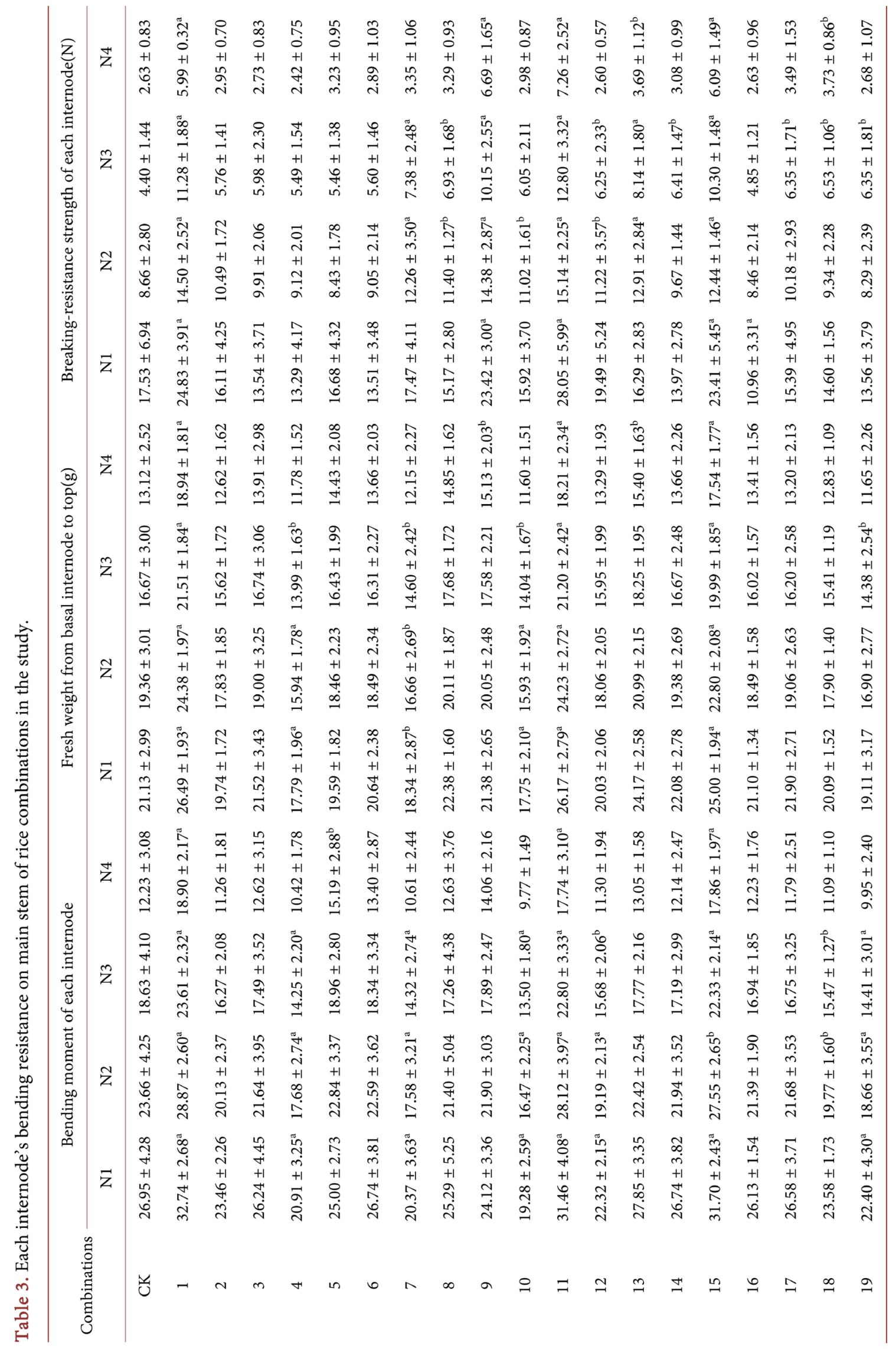




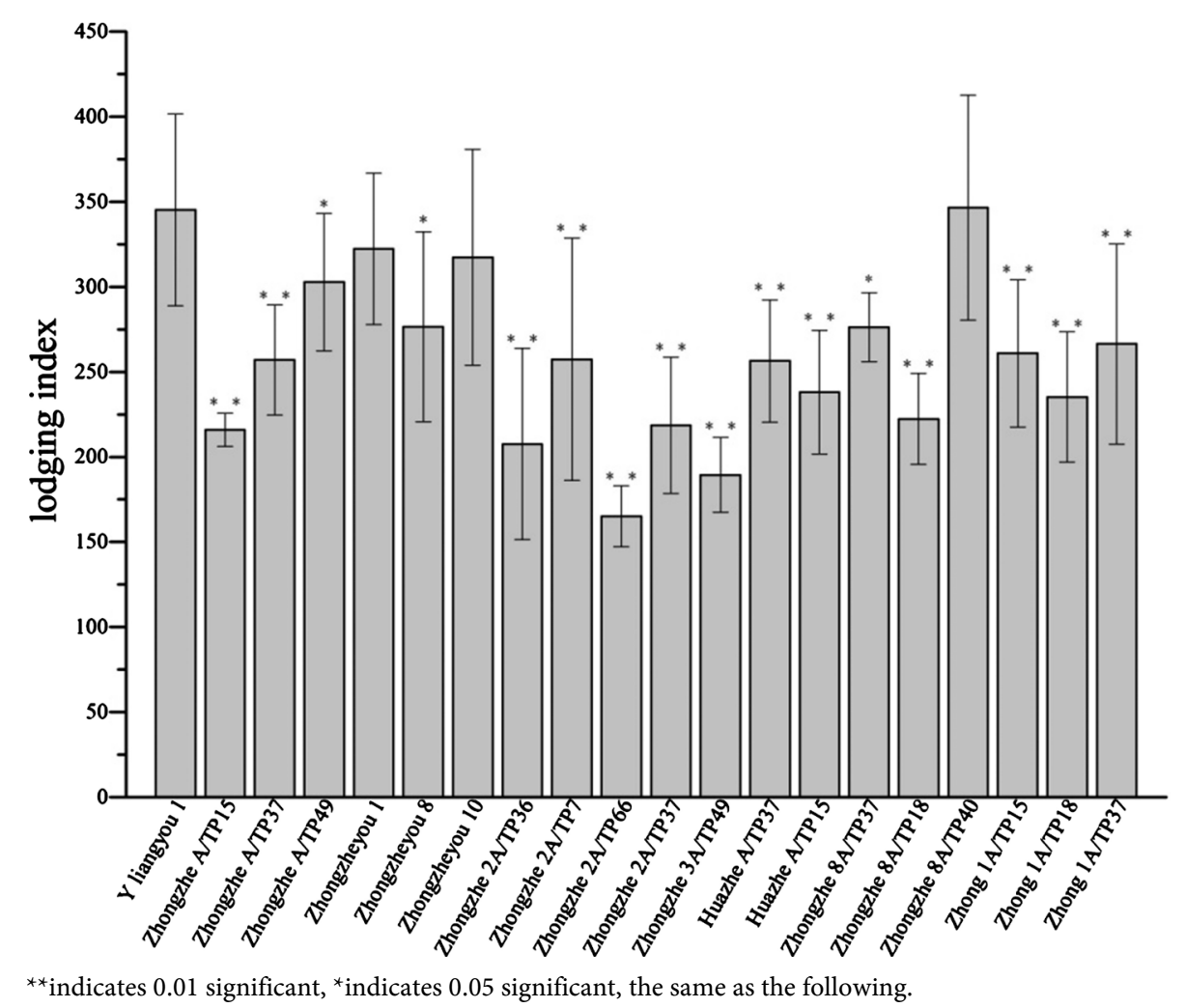

Figure 1. Lodging index of 20 rice combinations in the study.

significant negative correlation between the basal to spike mass, the $3^{\text {rd }}$ dry mass, the $2^{\text {nd }}$ outer diameter, the $4^{\text {th }}$ section diameter and the lodging index (Figure 2).

Correlation analysis of the lodging traits data of the combination materials of Zhongzhe $2 \mathrm{~A}$ showed that the plant height and the second and third internode lengths were significantly positively correlated with the lodging index $(P<0.01)$, while the first internode length was the same. The bending moment, ear length and ear quality were significantly positively correlated with the lodging index $(P$ $<0.05$ ), while the section 2 dry mass, section 3 dry mass, section 4 dry mass and section 2 outer diameter and lodging index showed a significant negative correlation, and the outer diameter of the first section was significantly negatively correlated with the lodging index (Figure 3). Correlation analysis of the lodging traits data of the combined materials of Zhongzhe $3 \mathrm{~A}$ found that there was a significant positive correlation between the length of the second and third internode and the lodging index $(P<0.05)$, while the length of the fourth internode and the lodging index were significant negatively correlated (Figure 4 ).

Correlation analysis of the lodging traits data of the combination materials of Zhongzhe $8 \mathrm{~A}$ showed that there was a significant positive correlation between the length of the first, second and third sections and the lodging index $(P<$ $0.01)$. The length of the spikes was significantly positively correlated with the lodging index $(P<0.05)$. From the base of each section to the top of the spike, the dry mass of the second section, the dry mass of the third section, the length 


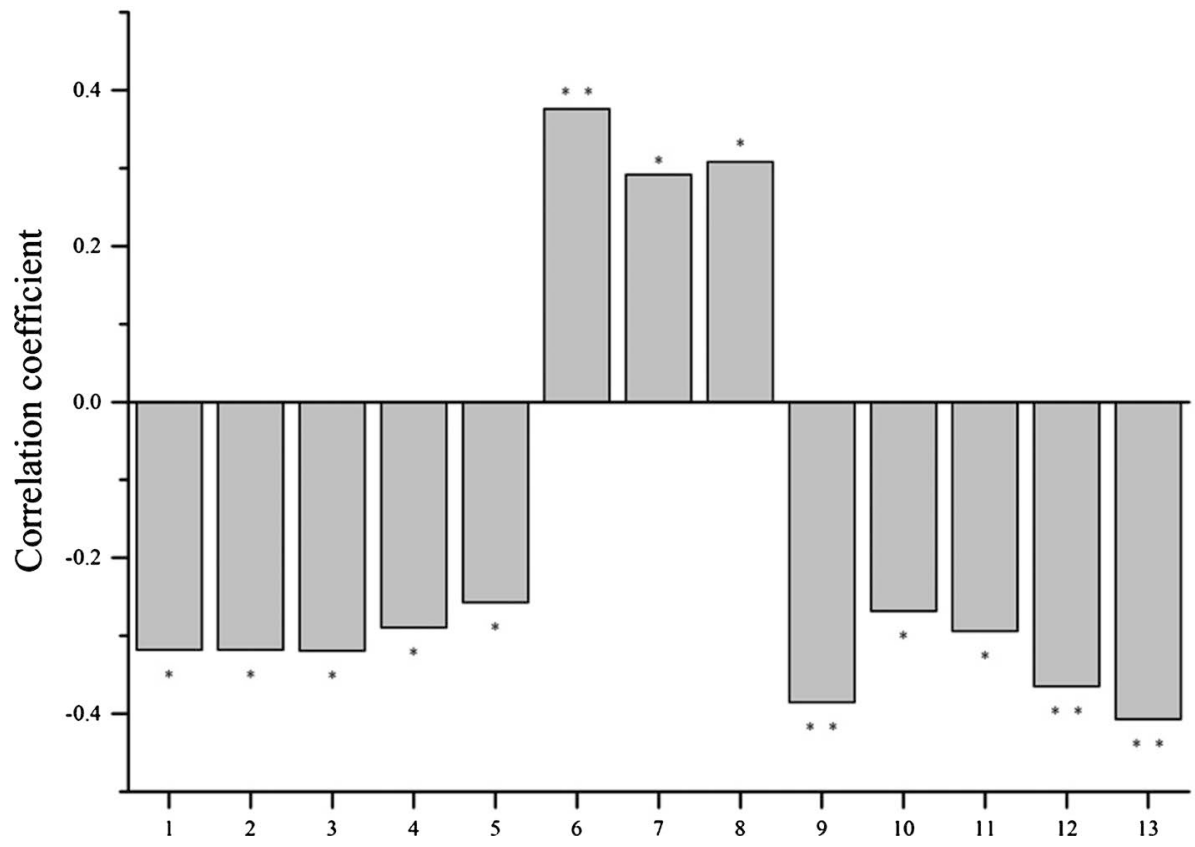

1: Fresh weight from $1^{\text {st }}$ basal internode to top; 2: Fresh weight from $2^{\text {nd }}$ basal internode to top; 3 : Fresh weight from $3^{\text {rd }}$ basal internode to top; 4: Fresh weight from $4^{\text {th }}$ basal internode to top; 5: Dry weight of $3^{\text {rd }}$ internode; 6: Length of $1^{\text {st }}$ internode; 7: Length of $2^{\text {nd }}$ internode; 8: Length of $3^{\text {rd }}$ internode; 9: Culm diameter of $1^{\text {st }}$ internode; 10: Culm diameter of $2^{\text {nd }}$ internode; 11: Culm diameter of $4^{\text {th }}$ internode; 12 : Grain number per panicle; 13: Grain density.

Figure 2. The significant correlated traits with lodging index in the combinations combined by Zhongzhe A.

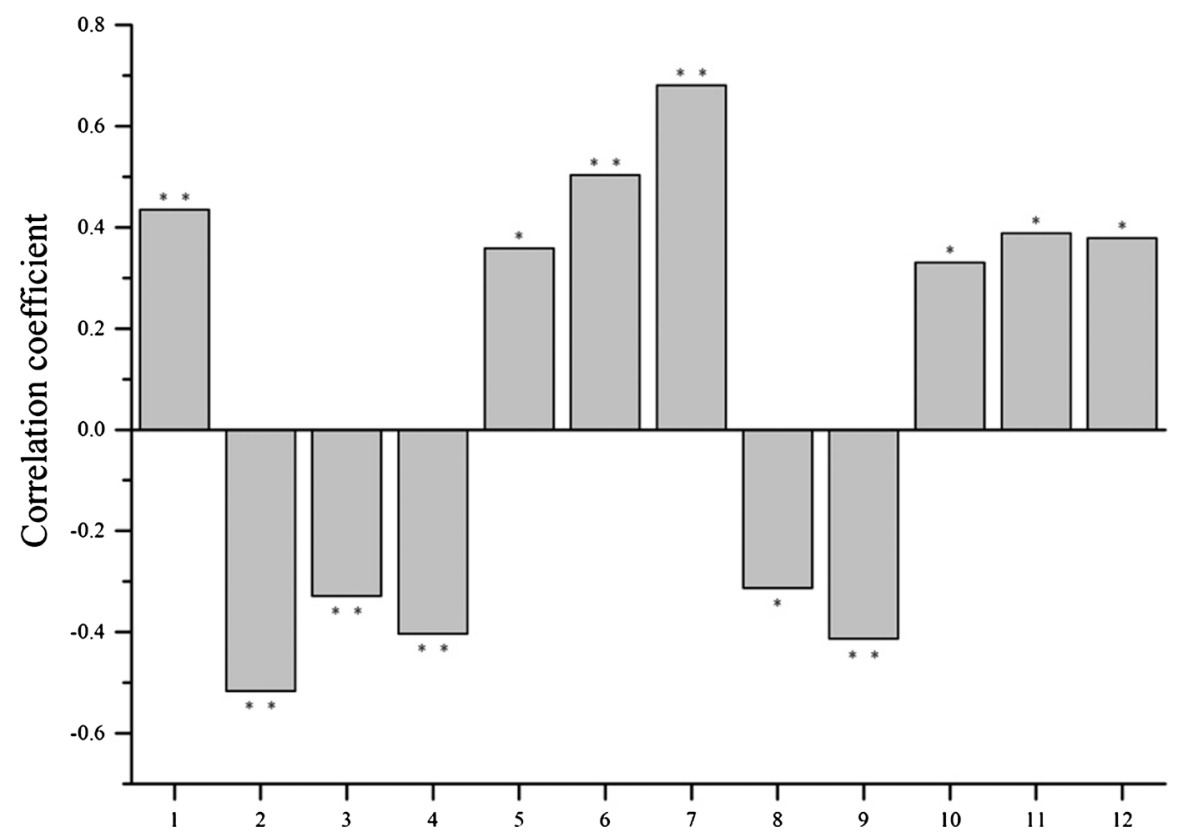

1: Plant height; 2: Dry weight of $2^{\text {nd }}$ internode; 3: Dry weight of $3^{\text {rd }}$ internode; 4 : Dry weight of $4^{\text {th }}$ internode; 5: Length of $1^{\text {st }}$ internode; 6: Length of $2^{\text {nd }}$ internode; 7: Length of $3^{\text {rd }}$ internode; 8: Culm diameter of $1^{\text {st }}$ internode; 9: Culm diameter of $2^{\text {nd }}$ internode; 10: Bending moment of $1^{\text {st }}$ internode; 11: Panicle length; 12: Fresh weight of panicle.

Figure 3. The significant correlated traits with lodging index in the combinations combined by Zhongzhe $2 \mathrm{~A}$. 


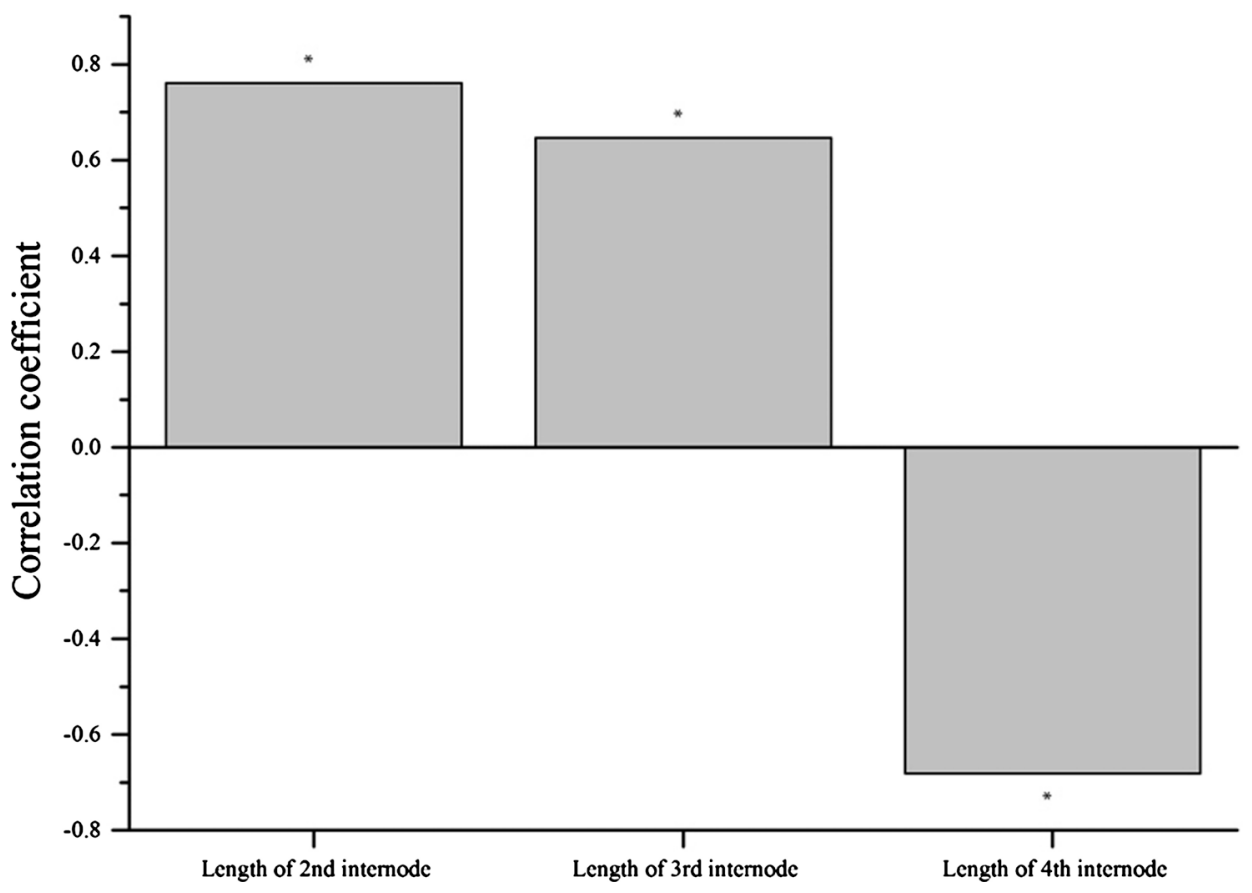

Figure 4. The significant correlated traits with lodging index in the combinations combined by Zhongzhe $3 \mathrm{~A}$.

of the fourth section, the outer diameter of the third section, the outer diameter of the fourth section, the bending moment of the second section, and the bending moment of the third section, there was a significant negative correlation between the bending moment and the lodging index in section 4 and a significant negative correlation between the second section outer diameter and the first section bending moment and lodging index (Figure 5). Correlation analysis of the lodging traits data of the combination materials of Huazhe A found that the mass of the $2^{\text {nd }}$ basal to spike top and the 4 th outer diameter were significantly negatively correlated with the lodging index $(P<0.01)$. The base of the first section was spike mass, first section dry mass, second section outer diameter; the first section bending moment, grain per panicle and grain density were significantly negatively correlated with the lodging index $(P<0.05)$ (Figure 6).

Correlation analysis of the lodging traits data of the combined materials of Zhong 1A showed that there was a significant positive correlation between the first and second internode lengths and the lodging index $(P<0.01)$, while the third section from the base to the top quality, section 4 from the base to the top quality, section 2 dry mass, section 4 dry mass and section 4 bending moment were significantly negatively correlated with the lodging index. The mass from the base of the 1st segment to the top of the spike, the base of the 2nd segment to the top of the spike mass, section 4 length, section 3 outer diameter, section 2 bending moment, section 3 bending moment, grain number per panicle and grain density were significantly negatively correlated with the lodging index $(P<$ 0.05) (Figure 7). 


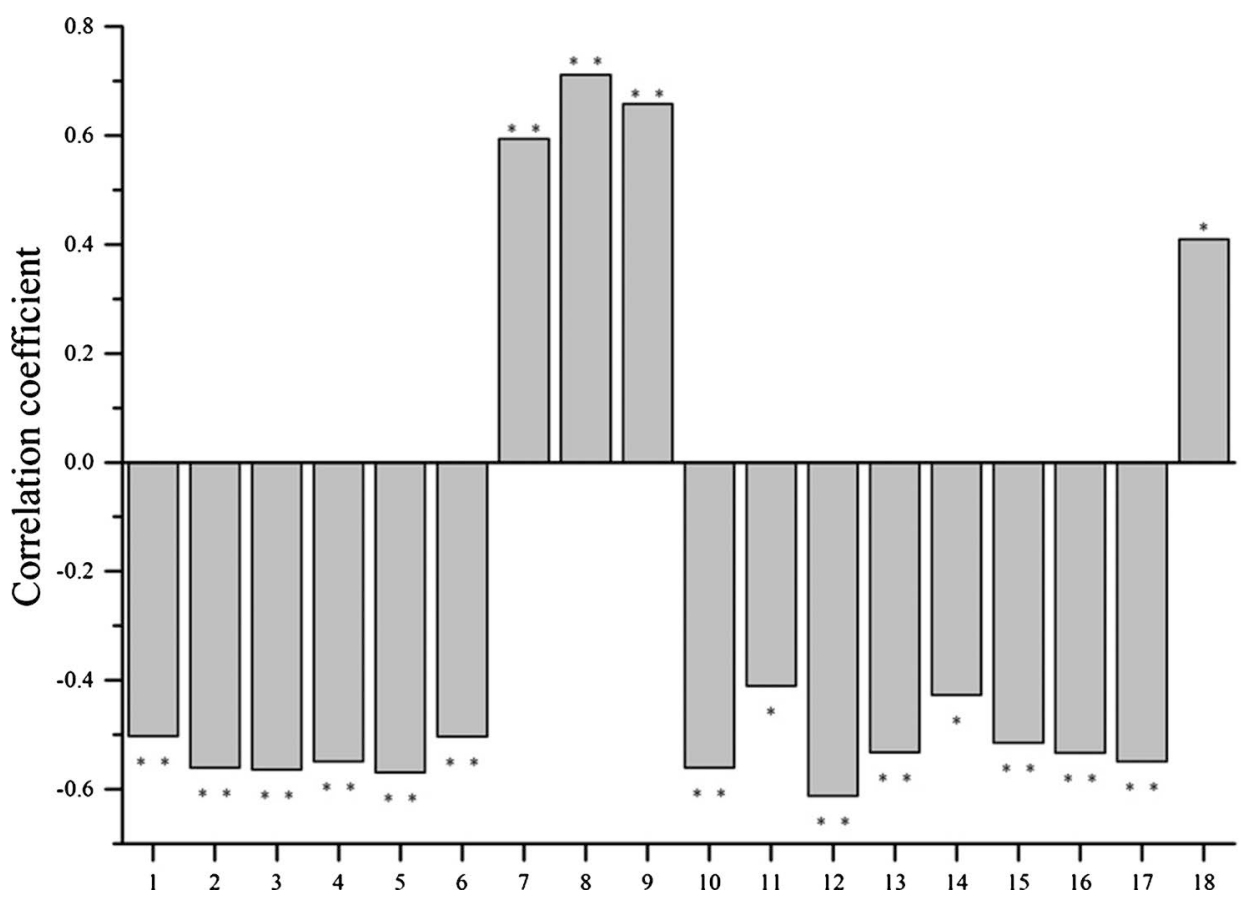

1: Fresh weight from $1^{\text {st }}$ basal internode to top; 2: Fresh weight from $2^{\text {nd }}$ basal internode to top; 3: Fresh weight from $3^{\text {rd }}$ basal internode to top; 4: Fresh weight from $4^{\text {th }}$ basal internode to top; 5: Dry weight of $2^{\text {nd }}$ internode; 6: Dry weight of $3^{\text {rd }}$ internode; 7: Length of $1^{\text {st }}$ internode; 8: Length of $2^{\text {nd }}$ internode; 9: Length of $3^{\text {rd }}$ internode; 10: Length of $4^{\text {th }}$ internode; 11: Culm diameter of $2^{\text {nd }}$ internode; 12: Culm diameter of $3^{\text {rd }}$ internode; 13: Culm diameter of $4^{\text {th }}$ internode; 14: Bending moment of $1^{\text {st }}$ internode; 15: Bending moment of $2^{\text {nd }}$ internode; 16: Bending moment of $3^{\text {rd }}$ internode; 17: Bending moment of $4^{\text {th }}$ internode; 18: Panicle length.

Figure 5. The significant correlated traits with lodging index in the combinations combined by Zhongzhe 8A.

\section{Discussion}

\subsection{Evaluation of the Anti-Lodging Ability of the Combination of Zhongzheyou Series}

In this study, 19 rice materials were prepared by Zhongzhe A, and its derived lines were selected. Y Liangyou 1 was used as a control, including for comprehensive plant height [3] [4], for stem-related traits [9] [10] [11] and for several traits related to rice lodging that have been reported and analyzed by predecessors, such as spike type [12] [13]. Because the lodging index takes into account the characteristics of rice plant height, fresh quality and other mechanical characteristics such as stem bending force and so on, it has a strong comprehensive evaluation performance [19], so this study uses the lodging index to measure the resistance of the rice varieties to the lodging ability. The higher the lodging index, the easier it is for the stem to fall down.

By comparing the lodging index of 19 rice materials, it was found that the lodging index of 18 materials was smaller than that of the control Y Liangyou 1, especially the 14 materials of Zhongzhe A/TP15, and the lodging index was significantly less $(P<0.01)$ than Y Liangyou 1 , which may be related to the selected CMS. Lan Caixia et al. [20] found that the parental selection is important to 


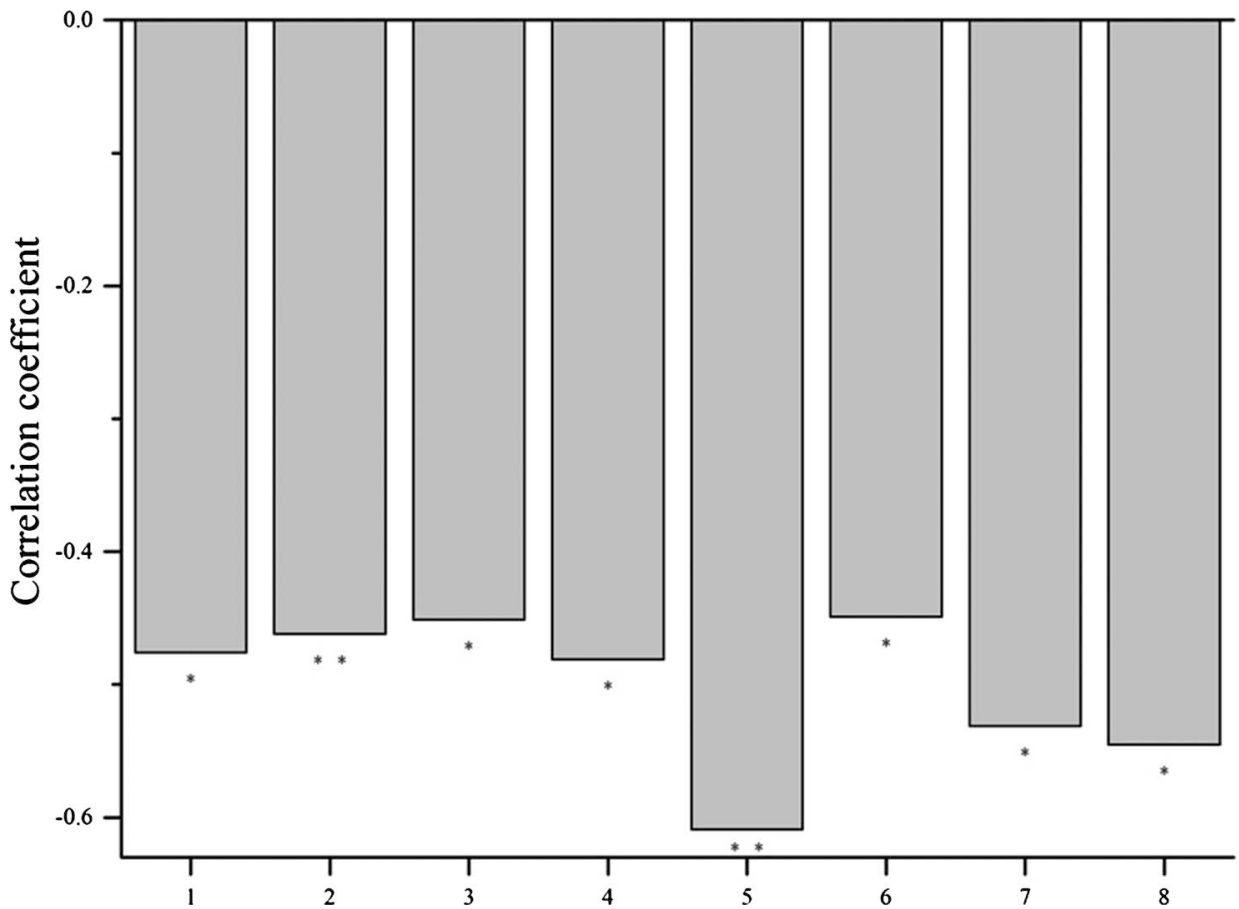

1: Fresh weight from $1^{\text {st }}$ basal internode to top; 2: Fresh weight from $2^{\text {nd }}$ basal internode to top; 3: Dry weight of $1^{\text {st }}$ internode; 4: Culm diameter of $2^{\text {nd }}$ internode; 5: Culm diameter of $4^{\text {th }}$ internode; 6: Bending moment of $1^{\text {st }}$ internode; 7: Grain number per panicle; 8: Grain density.

Figure 6. The significant correlated traits with lodging index in the combinations combined by Zhongzhe 16A.

avoid the occurrence of lodging in the analysis of the correlation between the lodging resistance of hybrid japonica rice and its parents. Ding Mingliang et al [21] found that the lodging resistance of the variety is closely related to its parents, and the selection of anti-falling varieties as parents can improve the lodging resistance of the cultivated varieties. The reason is that we always adhere to the main direction of shaping the ideal plant type and the heterosis utilization of Indica-japonica subspecies in the long-term breeding work. Furthermore, we have developed Zhongzhe A [16], Zhongzhe 2A, Zhongzhe 3A, and Zhongzhe 8A, Huazhe A and Zhong 1A and other batches of sterile lines with compact plant types and stout stalks, the use of these sterile lines bred in the varieties of Zhongzheyou 1 [17], Zhongzheyou 8 [22] and Zhongzheyou 10 [23] and other varieties have tall and straight, green rod ripening, the late resistance to lodging ability, and so on.

Nevertheless, if the lodging index 200 [3] is used as the critical value for lodging, only the lodging index of Zhongzhe 2A/TP66 and Zhongzhe 3A/TP49 is less than 200, which may be related to the recovery of these two materials, TP66 and TP49, and the ability to resist lodging is strong.

\subsection{Evaluation of Key Factors Affecting Lodging in Rice}

In this study, when we analyzed the lodging-related traits of 19 rice materials from Zhongzhe A and its derived lines, it was found that the correlation between 


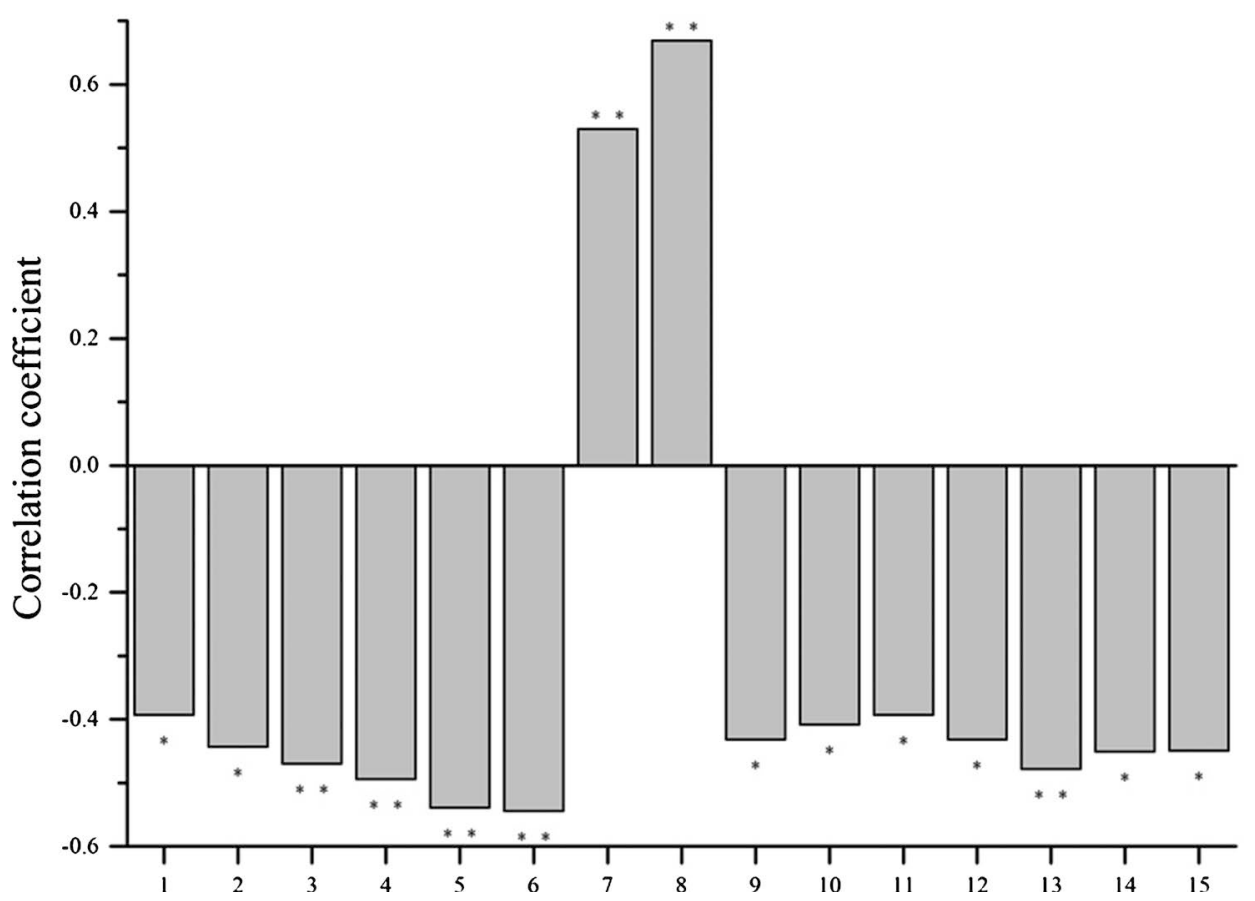

1: Fresh weight from $1^{\text {st }}$ basal internode to top; 2: Fresh weight from $2^{\text {nd }}$ basal internode to top; 3: Fresh weight from $3^{\text {rd }}$ basal internode to top; 4 : Fresh weight from $4^{\text {th }}$ basal internode to top; 5: Dry weight of $2^{\text {nd }}$ internode; 6: Dry weight of $4^{\text {th }}$ internode; 7: Length of $1^{\text {st }}$ internode; 8: Length of $2^{\text {nd }}$ internode; 9: Length of $4^{\text {th }}$ internode; 10: Culm diameter of $3^{\text {rd }}$ internode; 11: Bending moment of $2^{\text {nd }}$ internode; 12: Bending moment of $3^{\text {rd }}$ internode; 13: Bending moment of $4^{\text {th }}$ internode; 14: Grain number per panicle; 15: Grain density.

Figure 7. The significant correlated traits with lodging index in the combinations combined by Zhong $1 \mathrm{~A}$.

plant height, stem-stalk correlation traits, spike type factor and lodging was consistent with that of previous research results.

In this study, only a significant positive correlation between plant height and lodging index was found in the combination of Zhongzhe $2 \mathrm{~A}$. This is consistent with previous research results. Plant height is not necessarily the most important determinant of rice lodging [3] [5] [6]. However, in the combination of Zhongzhe A, Zhongzhe 2A, Zhongzhe $3 \mathrm{~A}$, Zhongzhe $8 \mathrm{~A}$ and Zhong $1 \mathrm{~A}$, the second internode length and the lodging index were found to be extremely significant or significantly positively correlated with the results of studies by Yang Yanhua et al. [24], Yang Guotao et al. [25] and Shen Guangle et al. [26]. In the combination of Zhongzhe A, Zhongzhe 8A, Huazhe A and Zhong 1A, it was found that the bases of the first and second sections were significantly or significantly negatively correlated with the top weight and the lodging index, which indicated that in the late stage of grain filling, maintaining the stalk fresh green and the live stalk mature is conducive to improving the lodging resistance of rice [6], which is contrary to the research of Shen Guangle et al. [26]. This can be due to the findings of Shen Guangle et al. Fresh weight is so heavy that it becomes a constituent factor that causes lodging. In the combination of Zhongzhe A, Zhongzhe $2 \mathrm{~A}$ and Zhongzhe $8 \mathrm{~A}$, the third section of dry weight and the lodging index were 
significantly or significantly negatively correlated, and in the combination of Zhongzhe A, Zhongzhe 2A and Zhongzhe 8A and Huazhe A, the $2^{\text {nd }}$ section OD and the lodging index showed a significant or extremely significant negative correlation, which is consistent with the research of Shen Feng et al. [6] and Shen Guangle et al. [26]. Increasing the dry matter content of the stem and cultivating the strong stalk variety should be one of the strategies to preventing rice lodging.

The southern Indica rice, especially the large panicle hybrid Indica rice combination, has a short panicle neck and drooping ear, and the neck curvature is large. When the external force acts, the panicle neck swings with the wind to relieve the force of the stem to the base internode [27]. In the combination of Zhongzhe A, Huazhe A and Zhong 1A, it was found that the grain number per grain and the grain density were significantly or significantly negatively correlated with the lodging index, which may be due to the larger number of grains per panicle. The larger the grain density, the more favorable the ear sag, and the easier it is to cause the ear to swing with the wind, which is beneficial to alleviate the folding force of the stem to the base.

\subsection{The Lodging Resistance Improvement Strategy of the Combination of Zhongzheyou Series}

Although this study found that the lodging resistances of Zhongzhe A and its derived CMS lines were significantly higher than that of the control Y Liangyou 1, Zhongzheyou 1 was represented in the actual production process of rice. There is still a serious lodging in the late growth stage of the varieties that have been assembled and approved by Zhongzhe $\mathrm{A}$ and its derivative lines.

In view of the lodging resistance improvement of Zhongzhe $A$ and its derived CMS line materials, we believe that Zhongzhe A and Zhongzhe 8A should increase the outer diameter of the second section of the CMS line or use the second section. The coarser recovery system, the second internode length of the CMS line is reduced, or the second internode length is used to form a hybrid combination. For Zhongzhe 2A, it should be reduced by increasing the plant height, appropriately increasing the outer diameter of the second section of the sterile line, or selecting the recovery line of the second section with a larger outer diameter. Reducing the length of the second section of the CMS line or selecting the shorter length of the second section is used to assemble the hybrid combination. For Zhongzhe 3A, the hybridization combination should be combined by appropriately reducing the length of the $2^{\text {nd }}$ and $3^{\text {rd }}$ sections of the CMS line or using the shorter recovery line between the $2^{\text {nd }}$ and $3^{\text {rd }}$ sections. For Huazhe A, the hybridization combination should be combined by appropriately increasing the outer diameter of the second section of the CMS line or using the recovery line of the second outer diameter of the second section. For Zhong $1 \mathrm{~A}$, reduced length of the $1^{\text {st }}$ or $2^{\text {nd }}$ internodes of the CMS line or shorter restorer lines between the $1^{\text {st }}$ and $2^{\text {nd }}$ sections should be combined with the hybridization combination. 
The results showed that the physical characteristics of the $2^{\text {nd }}$ section of rice stalk were closely correlated with those of the lodging index of rice, which could be used as an effective index for the resistance of rice in the field to improve the yield of rice. However, we should also see that the rice lodging resistance is the result of many factors of the stem; they are mutually restrained to promote contradictory unity; only by rationally arranging them into an optimal combination can the stalk lodging resistance be maximized. In the actual promotion process of the variety, the difference in lodging resistance between different varieties should be fully considered and promoted according to the local condition.

\section{Acknowledgements}

We are grateful to anonymous reviewers. This work was supported by National Natural Science Foundation of China, grant 31701401 and two funds of Zhejiang Province Public Welfare Technology Application Research Project (LGN19C130005, 2016C32094).

\section{Conflicts of Interest}

The authors declare no conflicts of interest regarding the publication of this paper.

\section{References}

[1] Weber, C.R. and Fehr, W.R. (1966) Seed Yield Losses from Lodging and Combine Harvesting in Soybeans. Agronomy Journal, 58, 287-289. https://doi.org/10.2134/agronj1966.00021962005800030012x

[2] Setter, T.L., Laureles, E.V. and Mazaredo, A.M. (1997) Lodging Reduces Yield of Rice by Self Shading and Reductions in Canopy Photosynthesis. Field Crops Research, 49, 95-106. https://doi.org/10.1016/S0378-4290(96)01058-1

[3] Yang, H.J. and Li, Y.Z. (2000) Relationship between Stem Traits and Lodging Resistance of Rice. Fujian Journal of Agricultural Sciences, 15, 1-7. (In Chinese)

[4] Lin, H.X. and Zhuang, J.Y. (1996) Molecular Marker Localization of Quantitative Trait Loci in Rice Plant Height and Its Components. Acta Agronomica Sinica, 22, 257-263. (In Chinese)

[5] Zhang, Z.X. and Chen, W.F. (1999) Relationship between Lodging Resistance of Rice and Physical Properties of Stem and Its Effect on Yield. Journal of Shenyang Agricultural University, 30, 81-85. (In Chinese)

[6] Shen, F., Zhang, Z.X., Wang, Y., et al. (2003) Study on Lodging Traits of Super Hybrid Japonica Rice in Northeast China. Journal of Shenyang Agricultural University, 34, 161-164. (In Chinese)

[7] Wei, F.Z., Li, J.C., Qu, H.J., et al. (2010) Effects of Nitrogen Application Patterns on Winter Wheat Freezing Injury and Stalk Lodging Resistance of Winter Wheat. Jiangsu Journal of Agricultural Sciences, 26, 696-699. (In Chinese)

[8] Zou, D.T. and Qiu, T.Q. (1997) Correlation and Path Analysis of Rice Lodging Index and Other Traits. Journal of Northeast Agricultural University, 28, 112-118. (In Chinese) 
[9] Ookawa, T., Hobo, T., Yano, M., et al. (2010) New Approach for Rice Improvement Using a Pleiotropic QTL Gene for Lodging Resistance and Yield. Nature Communications, 1, 132. https://doi.org/10.1038/ncomms1132

[10] Kashiwagi, T., Togawa, E., Hirotsu, N., et al. (2008) Improvement of Lodging Resistance with QTLs for Stem Diameter in Rice (Oryza sativa L.). Theoretical and Applied Genetics, 117, 749-757. https://doi.org/10.1007/s00122-008-0816-1

[11] Kashiwagi, T., Hirotsu, N., Ujiie, K. and Ishimaru, K. (2010) Lodging Resistance Locus pr/5 Improves Physical Strength of the Lower Plant Part under Different Conditions of Fertilization in Rice (Oryza sativa L.). Field Crops Research, 115, 107-115. https://doi.org/10.1016/j.fcr.2009.10.011

[12] Li, H.J., Zhang, X.J., Li, W.J., et al. (2009) Comparison of Lodging Resistance of Different Panicle Type Japonica Rice Varieties. Chinese Journal of Rice Science, 2, 191-196. (In Chinese)

[13] Xu, Z.J., Zhang, S.L., Zhou, S.Q., et al. (2004) Preliminary Analysis of the Relationship between Rice Panicle Type and Lodging Resistance. Plant Physiology Communications, 40, 561-563.

[14] Du, X.L., Fang, X.Q., Liu, W., et al. (2004) Theoretical Analysis and Simulation of the Relationship between Erect Panicle Type and Lodging Resistance in Rice. Journal of Jilin Agricultural Sciences, 29, 3-4. (In Chinese)

[15] Zhao, A.Q., Yuan, Z.H. and Cao, Q. (2006) Comprehensive Evaluation of Lodging Resistance of Rice Stalks. Journal of Biomathematics, 21, 554-556. (In Chinese)

[16] Zhang, S., Tong, H. and Tong, H. (2004) Breeding and Utilization of High Quality japonica Rice Sterile Line Zhongzhe A. Hybrid Rice, 19, 11-13. (In Chinese)

[17] Zhang, S., Tong, H., Cao, Y., et al. (2005) Breeding and Application of a New High Quality and High Yield Hybrid Japonica Rice Combination Zhongzheyou No. 1. Hybrid Rice, 20, 21-22. (In Chinese)

[18] Seko, H. (1962) Studies in Lodging in Rice Plants. Bulletin Kyushu National Agricultural Experiment Station, 7, 419-499. (In Japanese)

[19] Ma, J., Ma, W., Tian, Y., et al. (2004) Study on Lodging Resistance of Heavy Panicle Rice Plants. Acta Agronomica Sinica, 30, 143-148. (In Chinese)

[20] Ma, R. (2009) Preliminary Study on Lodging Resistance of Rice Stems in Cold Land. Northern Rice, No. 5, 13-15. (In Chinese)

[21] Ding, M., Su, Z., Zou, W., et al. (2012) Relationship between Lodging Resistance and Agronomic Traits and Parental Lodging Resistance of Highland japonica Rice. Chinese Journal of Rice Science, 26, 325-330. (In Chinese)

[22] Cao, Y., Tong, H., Tang, C., et al. (2008) Breeding and Cultivation Techniques of High Quality Hybrid japonica Rice Zhongzheyou No. 8. China Rice, No. 4, 27-28. (In Chinese)

[23] Cao, Y., Zhang, S., Tang, C., et al. (2013) Breeding and Application of a New High-Yield Three-Line Hybrid japonica Rice Combination Zhongzheyou No. 10. Hybrid Rice, No. 1, 16-18. (In Chinese)

[24] Yang, Y., Zhu, Z., Zhang, Y., et al. (2011) Relationship between Lodging Resistance and Stem Morphological Traits of Different Rice Varieties (Lines). Jiangsu Journal of Agricultural Sciences, 27, 231-235. (In Chinese)

[25] Yang, G., Xie, C. and Chen, Y. (2007) Study on Lodging Resistance Characteristics of B803A Rice Varieties. Southwest China Journal of Agricultural Sciences, 20, 1162-1165. (In Chinese)

[26] Shen, G., Quartz, Huang, Y., et al. (2007) Study on Lodging Resistance of Rice and 
Its Correlation with Stem Traits. Chinese Agricultural Science Bulletin, 23, 58-62. (In Chinese)

[27] Deng, W., Qing, X., Ma, G., et al. (2006) Advances in Research on Lodging Resistance of Rice. Hybrid Rice, 21, 6-10. (In Chinese) 